\title{
Optimization of Microstructure and Mechanical Properties of Co-Cr-Mo Alloys by High-Pressure Torsion and Subsequent Short Annealing
}

\author{
Murat Isik ${ }^{1, * 1}$, Mitsuo Niinomi ${ }^{2, * 2}$, Huihong $\mathrm{Liu}^{3}$, Ken $\mathrm{Cho}^{4}$, Masaaki Nakai ${ }^{2}$, Zenji Horita ${ }^{5,6}$, \\ Takayuki Narushima ${ }^{7}$ and Kyosuke Ueda ${ }^{7}$ \\ ${ }^{1}$ Department of Materials Science, Tohoku University, Sendai 980-8579, Japan \\ ${ }^{2}$ Institute for Materials Research, Tohoku University, Sendai 980-8577, Japan \\ ${ }^{3}$ Joining and Welding Research Institute, Osaka University, Ibaraki 567-0047, Japan \\ ${ }^{4}$ Graduate School of Engineering, Osaka University, Suita 565-0871, Japan \\ ${ }^{5}$ Department of Materials Science and Engineering, Faculty of Engineering, Kyushu University, Fukuoka 819-0395, Japan \\ ${ }^{6}$ WPI, International Institute for Carbon-Neutral Energy Research (WPI-I2CNER), Kyushu University, Fukuoka 819-0395, Japan \\ ${ }^{7}$ Department of Materials Processing, Tohoku University, Sendai 980-8579, Japan
}

The main target of this study is to optimize the microstructure and to achieve an optimization for the mechanical properties in a biomedical Co-Cr-Mo (CCM) alloy with the nominal composition of Co-28Cr-6Mo (mass\%) subjected to high-pressure torsion (HPT) and subsequent short annealing. The $\gamma \rightarrow \varepsilon$ phase transformation and grain refinement occur in the CCM alloy subjected to HPT processing at an equivalent strain $\left(\varepsilon_{\mathrm{eq}}\right)$ of $2.25\left(\mathrm{CCM}_{\mathrm{HPT}}\right)$. The HPT processing causes a decrease in the elongation due to the formation of an excessive amount of $\varepsilon$ phase. For removal of the excessive amount of $\varepsilon$ phases, the $\mathrm{CCM}_{\mathrm{HPT}}$ was subjected to a short annealing $\left(\mathrm{CCM}_{\mathrm{HPTA}}\right)$. The effect of the short annealing temperature $(1073 \mathrm{~K}, 1273 \mathrm{~K}$, and $1473 \mathrm{~K}$; annealing time was fixed at $0.3 \mathrm{ks})$ on $\mathrm{CCM}_{\mathrm{HPT}}$ was investigated. In addition, the effect of the length of duration for the short annealing $\left(0.06 \mathrm{ks}, 0.3 \mathrm{ks}\right.$, and $0.6 \mathrm{ks}$;) for a fixed annealing temperature of $1273 \mathrm{~K}$ on $\mathrm{CCM}_{\mathrm{HPT}}$ was studied. $\mathrm{CCM}_{\mathrm{HPTA}(1273 \mathrm{~K})}$ annealed for $0.3 \mathrm{ks}$ shows a good optimization of mechanical properties that include high strength and large elongation owing to its ultrafine-grained microstructure, and removal of excessive $\varepsilon$ phases. [doi:10.2320/matertrans.M2016112]

(Received March 28, 2016; Accepted August 24, 2016; Published September 30, 2016)

Keywords: cobalt-chromium-molybdenum alloys, biomaterials, high-pressure torsion, grain refinement, short annealing

\section{Introduction}

CCM alloys have been widely used as implant materials in biomedical applications such as hip and knee joints because of their excellent mechanical properties and good biocompatibility. ${ }^{1-3)}$ The mechanical properties of CCM alloys need to be further improved to reduce the probability of failure in biomedical applications. ${ }^{4)}$ Grain refinement is effective to improve the mechanical properties of CCM alloys. In fact, CCM alloys with small grain size have been practically used. ${ }^{5)}$ It

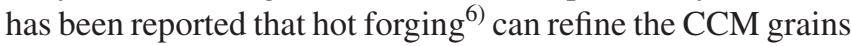
from an initial size of $40 \mu \mathrm{m}$ to $0.6 \mu \mathrm{m}$. ${ }^{6}$ However, grain refinement to a nano-scale is difficult to be achieved by the conventional processing methods.

The processing of metals with severe plastic deformation offers the potential for achieving extraordinary grain refinement in metals. ${ }^{7)}$ Several severe plastic deformation methods have been utilized so far, and among them most interest has been placed on equal-channel angular pressing (ECAP) ${ }^{8,9)}$ and high-pressure torsion (HPT) ${ }^{10)}$ In general, processing by ECAP, where a rod is pressed through a die constrained within a channel, causes grain refinement on the micrometer scale, ${ }^{8)}$ while HPT processing, where a disk is subjected to a high applied pressure and torsional straining, causes grains to be refined on the nanometer level. ${ }^{7,10)}$ The large numbers of dislocations introduced by HPT processing rearrange and aggregate to form dislocation cells. Subsequently, the dislocation rearrangement increases the misorientation between the cells thereby causing the formation of low-angle and then

\footnotetext{
${ }^{* 1}$ Graduate Student, Tohoku University

${ }^{* 2}$ Corresponding author, E-mail: niinomi@imr.tohoku.ac.jp
}

high-angle grain boundaries. ${ }^{9-11)}$ In addition, HPT processing, which can induce a very high strain, ${ }^{12)}$ may cause phase transformations in some metallic materials. It has been known that inducing a high strain can cause $\gamma \rightarrow \varepsilon$ transformation in Co-Cr-Mo (CCM) alloys. ${ }^{13)}$

It has been reported that HPT processing can significantly improve the strength of the CCM alloy via the $\gamma \rightarrow \varepsilon$ strain-induced martensitic transformation and grain refinement. However, HPT processed CCM alloys generally exhibit poor elongation $^{14)}$ even some previous studies report that ductility of $\varepsilon$ phase is not necessarily inferior to that of $\gamma$ phase ${ }^{15,16)}$ but transformed $\varepsilon$ phases can act as obstacles for pinning the dislocation gliding. Furthermore, an $\varepsilon$ phase with an hcp structure has limited slip systems, whereby it generally shows low ductility compared to that of $\gamma$ phase. Therefore poor elongation of HPT-processed CCM alloy is considered to be attributed to the excessive $\varepsilon$ phase. Thus, it is necessary to improve the elongation of the HPT-processed CCM alloy while keeping its strength still high.

A short annealing is expected to induce a recovery in the elongation and maintain a high tensile strength in the HPT-processed CCM alloy by optimizing the volume fraction and distribution of the $\varepsilon$ phase while keeping the ultrafine-grained microstructure in the alloy.

In this study, the aim was to obtain optimized mechanical properties in the CCM alloy as a combination of high strength and large elongation by means of conducting a short annealing after HPT processing. The short annealing conditions including temperature and time were optimized. The effects of short annealing temperature and time on the microstructure and mechanical properties of the HPT processed CCM alloy were comprehensively investigated. 


\section{Experimental Procedures}

\subsection{Material preparation}

A cylindrical rod of a hot forged CCM alloy with a nominal composition of $\mathrm{Co}-28 \mathrm{Cr}-6 \mathrm{Mo}$ (mass $\%$ ) alloy with a diameter of $25 \mathrm{~mm}$ and a length of $50 \mathrm{~mm}$ was used in this study. The chemical composition of the CCM alloy is listed in Table 1 . The rod was subjected to solution treatment at $1473 \mathrm{~K}$ for $3.6 \mathrm{ks}$ in vacuum (hereafter designated as $\mathrm{CCM}_{\mathrm{ST}}$ ). The $\mathrm{CCM}_{\mathrm{ST}}$ rod was machined to disk-shaped specimens with diameters of $10 \mathrm{~mm}$ and thicknesses of $1 \mathrm{~mm}$ for HPT processing. The $\mathrm{CCM}_{\mathrm{ST}}$ disk was subjected to HPT processing under quasi-constrained conditions, in which the lower anvil was rotated 0.25 times with a rotation speed of $1 \mathrm{rpm}$ $\left(0.1220 \mathrm{rad} \mathrm{s}^{-1}\right)$ under a pressure of $6 \mathrm{GPa}$ in air at room temperature (hereafter designated as $\mathrm{CCM}_{\mathrm{HPT}}$ ). Then, the $\mathrm{CCM}_{\mathrm{HPT}}$ was subjected to a short annealing (hereafter designated as $\left.\mathrm{CCM}_{\mathrm{HPTA}}\right)$. The short annealings (duration was fixed at $0.3 \mathrm{ks})$ were conducted at $1073 \mathrm{~K}\left(\mathrm{CCM}_{\mathrm{HPTA}(1073 \mathrm{~K})}\right)$, $1273 \mathrm{~K}\left(\mathrm{CCM}_{\mathrm{HPTA}(1273 \mathrm{~K})}\right)$, and $1473 \mathrm{~K}\left(\mathrm{CCM}_{\mathrm{HPTA}(1473 \mathrm{~K})}\right)$ in order to investigate the effect of short annealing temperature on $\mathrm{CCM}_{\mathrm{HPT}}$. In addition, the short annealings (temperature was fixed at $1273 \mathrm{~K}$ ) were conducted for $0.06 \mathrm{ks}$ $\left(\mathrm{CCM}_{\mathrm{HPTA}(0.06 \mathrm{ks})}\right), \quad 0.3 \mathrm{ks} \quad\left(\mathrm{CCM}_{\mathrm{HPTA}(0.3 \mathrm{ks})}\right), \quad$ and $0.6 \mathrm{ks}$ $\left(\mathrm{CCM}_{\mathrm{HPTA}(0.6 \mathrm{ks})}\right)$ for studying the effect of short annealing duration on $\mathrm{CCM}_{\mathrm{HPT}}$. Hereafter, the CCM alloy subjected to HPT and subsequent annealing at the temperature $\mathrm{T}$ for the duration of $t$, is designated by $\operatorname{CCM}_{\mathrm{HPTA}(\mathrm{T} / \mathrm{t})}$ as $\mathrm{CCM}_{\mathrm{HPTA}(1273 \mathrm{~K}, 0.3 \mathrm{ks})}$ for the case of $\mathrm{T}=1273 \mathrm{~K}$ and $\mathrm{t}=0.3 \mathrm{ks}$. The equivalent strain $\varepsilon_{\text {eq }}$ at a distance $r$ from the disk center

Table 1 Chemical composition of hot forged CCM alloy (mass\%).

\begin{tabular}{c|ccccccccc}
\hline Element & $\mathrm{Cr}$ & $\mathrm{Mo}$ & $\mathrm{Ni}$ & $\mathrm{Mn}$ & $\mathrm{Si}$ & $\mathrm{C}$ & $\mathrm{N}$ & $\mathrm{Fe}$ & $\mathrm{Co}$ \\
\hline & 27.7 & 5.87 & $<0.01$ & 0.58 & 0.50 & 0.045 & 0.14 & $<0.1$ & Bal. \\
\hline
\end{tabular}
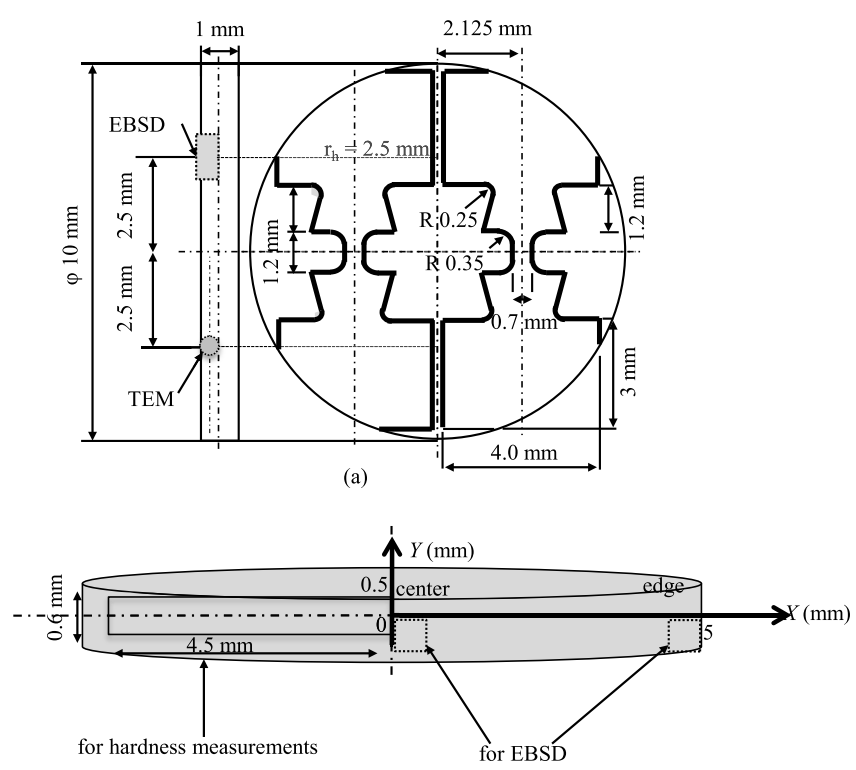

(b)

Fig. 1 (a) Positions for EBSD and TEM analyses and geometry of tensile test specimen and (b) hardness measurement positions for cross section of disk sample and EBSD analyses positions corresponding to hardness measurements. was estimated by the following equation: ${ }^{10)}$

$$
\varepsilon_{\mathrm{eq}}=2 \pi r N / t \sqrt{3}
$$

where $N$ is the rotation number and $t$ is the specimen thickness. $\varepsilon_{\text {eq }}$ was calculated according to eq. (1), as a function of distance from the disk center for $N=0.25$. As a result, the value of $\varepsilon_{\mathrm{eq}}$ is 2.25 for $N=0.25$ at the half radius, $\mathrm{r}_{\mathrm{h}}(r=$ $2.5 \mathrm{~mm}$ ). Additionally, $\mathrm{CCM}_{\mathrm{ST}}$ disks were also subjected to cold rolling with a thickness reduction of $50 \%\left(\varepsilon_{\mathrm{eq}}=0.8\right)^{17)}$ (hereafter designated as $\mathrm{CCM}_{\mathrm{CR}}$ ).

\subsection{Microstructural characterization}

The microstructures of specimens were characterized by electron backscatter diffraction analysis (EBSD) and transmission electron microscopy (TEM) using an accelerating voltage of $200 \mathrm{kV}$. The EBSD and TEM analyses were carried out at $\mathrm{r}_{h}$, which is $2.5 \mathrm{~mm}$ away from the disk center, as shown schematically in Fig. 1(a). Additionally, EBSD analyses were carried out at the center and edge of the cross section of the specimen, as shown in Fig. 1 (b). The specimens for EBSD analysis were wet-polished using water-proof emery papers up to \#2400 and were then buff-polished to obtain a mirror surface by a colloidal $\mathrm{SiO}_{2}$ suspension. For TEM sample preparation, the sample disk was fixed between two silicon substrates using an epoxy resin and then a thin plate was cut parallel to the cross section near the center of the disk sample. The plate was wet polished using water-proof emery papers up to \#2400. Then, a copper ring with a diameter of $3 \mathrm{~mm}$ was fixed on the polished plate at the $\mathrm{r}_{h}$ position using an epoxy resin. The thin plate was further thinned to less than $20 \mu \mathrm{m}$ using a dimple grinder and an ion-milling apparatus. Additional information about the TEM sample preparation was described and illustrated in details in a previous study. ${ }^{11)}$

\subsection{Mechanical tests}

An Instron-type testing machine was used for evaluating the tensile properties of the CCM alloys. The tensile tests were conducted at room temperature with a cross-head speed of $8.33 \times 10^{-6} \mathrm{~m} \cdot \mathrm{s}^{-1}$, which is equivalent to an initial strain rate of $6.94 \times 10^{-3} \mathrm{~s}^{-1}$. The tensile specimens were obtained from disk-shaped samples and the schematic drawing, is shown in Fig. 1 (a). ${ }^{14)}$ The tensile specimens were cut using a FANUC electric-discharge machine. The tensile specimens were wet-polished using water-proof emery papers up to \#1500 and thinned to a cross-sectional thickness of 0.5$0.6 \mathrm{~mm}$ (i.e., material up to a depth of $\sim 0.2-0.25 \mathrm{~mm}$ was removed from both surfaces of the specimen).

Hardness measurements were carried out using a Vickers microhardness tester with a load of $4.9 \mathrm{~N}$ for a dwell time of $15 \mathrm{~s}$ on the surface of the specimens. The measurements on the cross section of the disk-shaped specimen were performed at the interval of $0.5 \mathrm{~mm}$ and $0.15 \mathrm{~mm}$ between the measurement positions in the radial direction and cross section depth direction.

\section{Results}

\subsection{Effects of short annealing temperature}

Figure 2 shows the EBSD phase map, inverse pole figure (IPF) map, kernel average misorientation (KAM) maps, the 

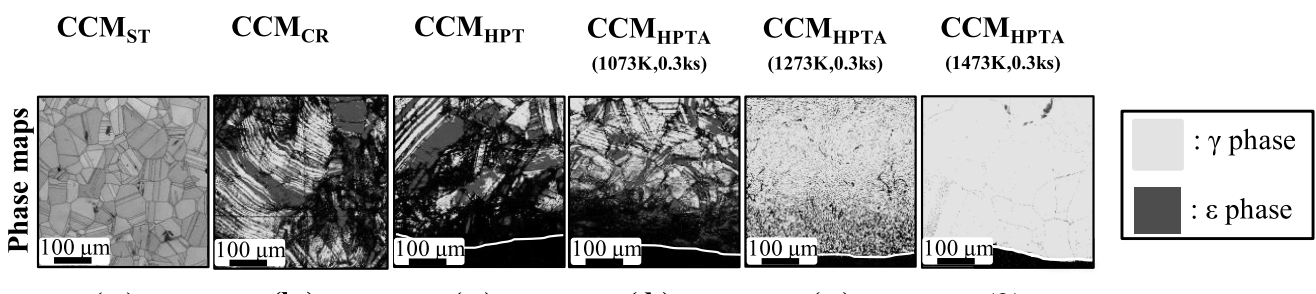

$\left(a_{1}\right)$

$\left(\mathbf{b}_{1}\right)$

$\left(\mathbf{c}_{1}\right)$

$\left(d_{1}\right)$

$\left(\mathbf{e}_{1}\right)$

(f)
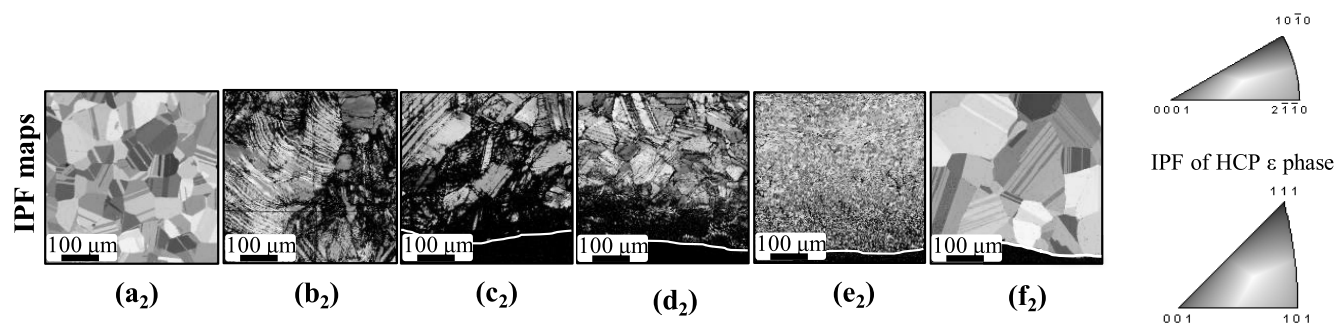

IPF of FCC $\gamma$ phase
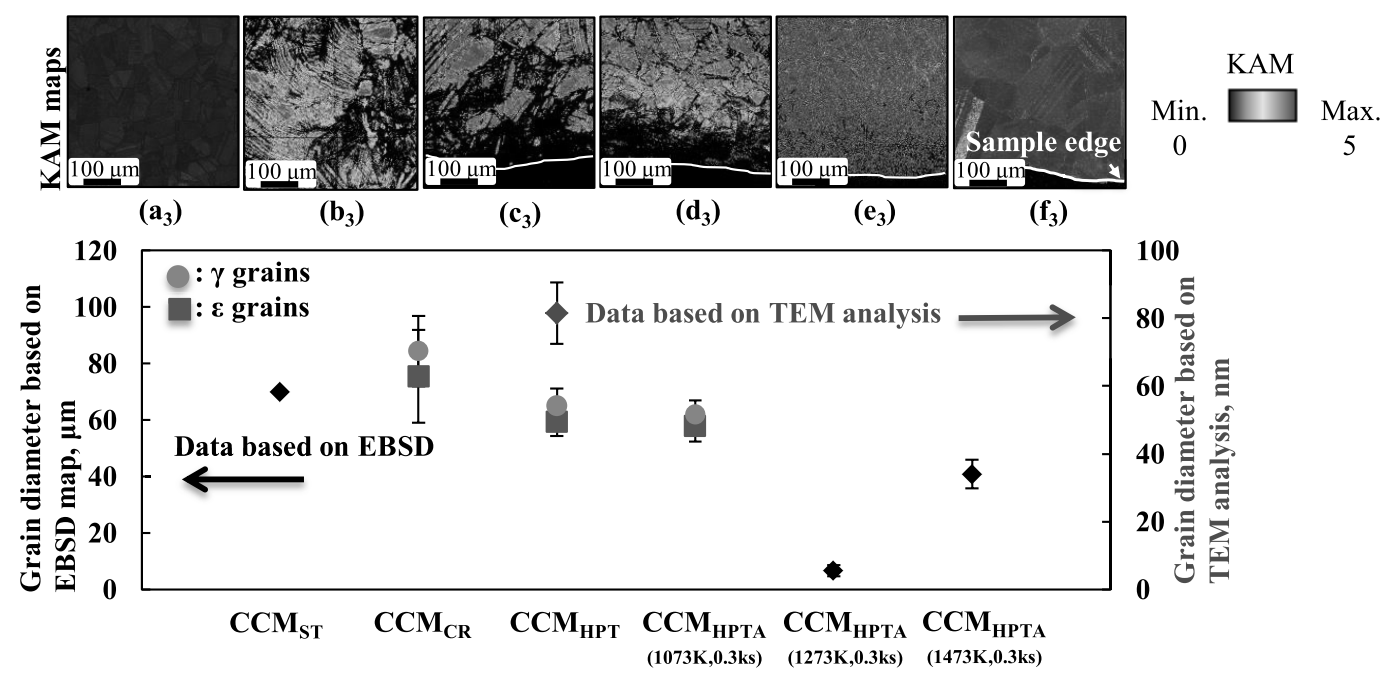

(g)

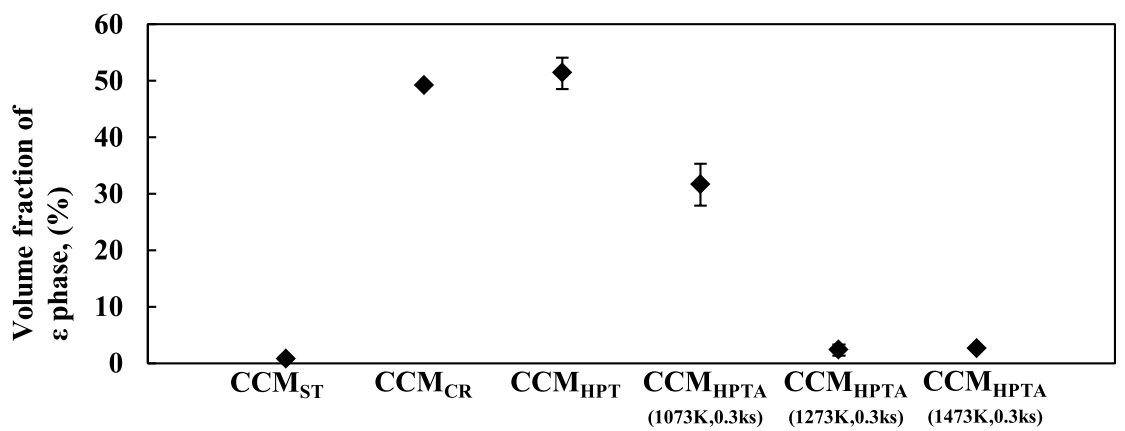

(h)

Fig. 2 EBSD $\left(\left(a_{1}\right)-\left(f_{1}\right)\right)$ phase, $\left(\left(a_{2}\right)-\left(f_{2}\right)\right)$ IPF and $\left(\left(a_{3}\right)-\left(f_{3}\right)\right)$ KAM maps and $(g)$ average grain diameter, and (h) volume fraction of $\varepsilon$ phases of CCM $\mathrm{CCM}_{\mathrm{CR}}, \mathrm{CCM}_{\mathrm{HPT}}, \mathrm{CCM}_{\mathrm{HPTA}(1073 \mathrm{~K}, 0.3 \mathrm{ks})}, \mathrm{CCM}_{\mathrm{HPTA}(1273 \mathrm{~K}, 0.3 \mathrm{ks})}$, and $\mathrm{CCM}_{\mathrm{HPTA}(1473 \mathrm{~K}, 0.3 \mathrm{ks})}$ based on EBSD analysis.

average grain diameter, and volume fractions of $\varepsilon$ phases of $\mathrm{CCM}_{\mathrm{ST}}, \quad \mathrm{CCM}_{\mathrm{CR}}, \quad \mathrm{CCM}_{\mathrm{HPT}}, \quad$ and $\mathrm{CCM}_{\mathrm{HPTA}(1073 \mathrm{~K})}$, $\mathrm{CCM}_{\mathrm{HPTA}(1273 \mathrm{~K})}$, and $\mathrm{CCM}_{\mathrm{HPTA}(1473 \mathrm{~K})}$ for $0.3 \mathrm{ks}$. The EBSD phase maps show that $\mathrm{CCM}_{\mathrm{ST}}$ consists almost entirely of a face centered cubic (fcc) $\gamma$ phase, whereas $\mathrm{CCM}_{\mathrm{HPT}}$, $\mathrm{CCM}_{\mathrm{HPTA}(1073 \mathrm{~K})}, \mathrm{CCM}_{\mathrm{HPTA}(1273 \mathrm{~K})}$, and $\mathrm{CCM}_{\mathrm{HPTA}(1473 \mathrm{~K})}$ have dual-phase microstructure, composed of the $\gamma$ and hexagonal close packed (hcp) $\varepsilon$ phase.

It has been reported that volume fraction of $\varepsilon$ phase is around $87 \%$ based on X-ray diffraction (XRD) analysis in $\mathrm{CCM}_{\mathrm{HPT}}{ }^{18)}$. Volume fraction of $\varepsilon$ phase in $\mathrm{CCM}_{\mathrm{HPTA}(1073 \mathrm{~K}, 0.3 \mathrm{ks})}(\sim 31 \%)$ is higher than those in $\mathrm{CCM}_{\mathrm{HPTA}(1273 \mathrm{~K}, 0.3 \mathrm{ks})}$ and $\mathrm{CCM}_{\mathrm{HPTA}(1473 \mathrm{~K}, 0.3 \mathrm{ks})}(\sim 2 \%)$, and lower than that in $\mathrm{CCM}_{\mathrm{HPT}},(\sim 51 \%)$, as shown in Fig. 2 (h). This decrease in volume fraction of $\varepsilon$ phase in $\mathrm{CCM}_{\mathrm{HPTA}(1073 \mathrm{~K}, 0.3 \mathrm{ks})}$ compared to $\mathrm{CCM}_{\mathrm{HPT}}$ is attributed to inhomogeneous microstructure caused by HPT processing.

The corresponding IPF maps suggest that the microstruc- 


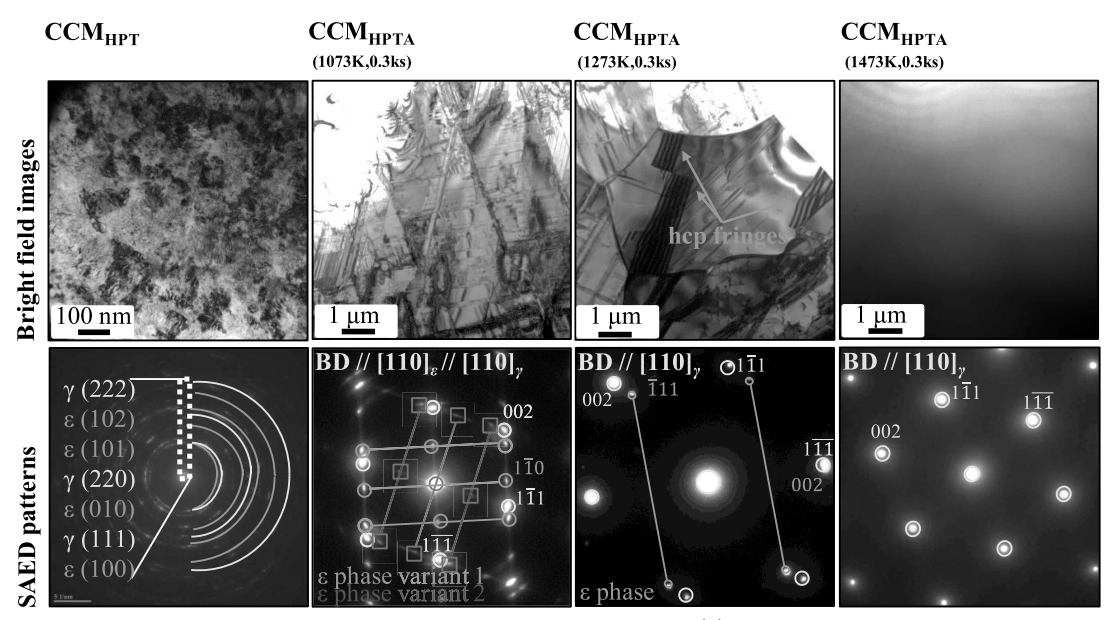

(a)

(b)

(c)

(d)

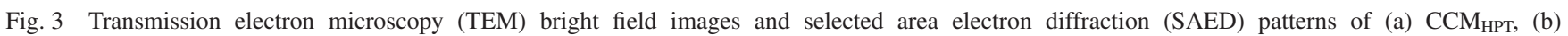

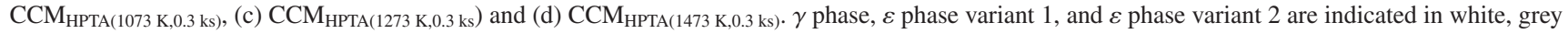
(circle) and grey (square), respectively, in the corresponding key diagrams of the SAED patterns. Beam direction is parallel to [110] $]_{\gamma}$ direction.

ture of $\mathrm{CCM}_{\mathrm{ST}}$ consists of equiaxed grains with an average diameter of $\sim 70 \mu \mathrm{m}$, presenting a random orientation distribution. Black areas, which possess a confidence index (CI) smaller than 1 , are seen in the IPF map of $\mathrm{CCM}_{\mathrm{HPT}}$. It has been reported that these black areas may originate from high strain or nanocrystalline microstructures. ${ }^{14)}$ Therefore, $\mathrm{CCM}_{\mathrm{HPT}}$ may show a heterogeneous microstructure consisting of grains in the micrometer and nanometer scale, or grains containing high and low strain. Average grain diameter of $\gamma$ phase grains in $\mathrm{CCM}_{\mathrm{HPT}}$ is $\sim 59 \mu \mathrm{m}$, while that of $\varepsilon$ phase grains is $\sim 65 \mu \mathrm{m}$ based on EBSD analysis.

These black areas are also observed in the IPF map of $\mathrm{CCM}_{\mathrm{HPTA}}$ at $1073 \mathrm{~K}$. The average diameter of the visible $\gamma$ phase grains in $\mathrm{CCM}_{\mathrm{HPTA}(1073 \mathrm{~K}, 0.3 \mathrm{ks})}$ is $\sim 58 \mu \mathrm{m}$, while that of the visible $\varepsilon$ phase grains is $\sim 62 \mu \mathrm{m}$ (Fig. 2 (g)). IPF maps of $\mathrm{CCM}_{\mathrm{HPTA}(1273 \mathrm{~K}, 0.3 \mathrm{ks})}$ and $\mathrm{CCM}_{\mathrm{HPTA}(1473 \mathrm{~K}, 0.3 \mathrm{ks})}$ do not show the existence of black areas, but do show recrystallized grains. Average grain diameter in $\operatorname{CCM}_{\mathrm{HPTA}(1473 \mathrm{~K}, 0.3 \mathrm{ks})}(\sim 42 \mu \mathrm{m})$ is larger than that of $\mathrm{CCM}_{\mathrm{HPTA}(1273 \mathrm{~K}, 0.3 \mathrm{ks})}(\sim 6.5 \mu \mathrm{m})$, as shown in Fig. 2 (g).

The EBSD KAM maps indicate that the strain of the CCM alloy shows a drastic increase through the HPT processing compared to that of the solution treated (ST) condition. High strain in $\mathrm{CCM}_{\mathrm{HPT}}$ still exists even though it is subjected to a subsequent short annealing at $1073 \mathrm{~K}\left(\mathrm{CCM}_{\mathrm{HPTA}(1073 \mathrm{~K}, 0.3 \mathrm{ks})}\right)$. Increasing the short annealing temperature causes a decrease in the strain $\left(\mathrm{CCM}_{\mathrm{HPTA}(1273 \mathrm{~K}, 0.3 \mathrm{ks})}\right.$ and $\left.\mathrm{CCM}_{\mathrm{HPTA}(1473 \mathrm{~K}, 0.3 \mathrm{ks})}\right)$.

Figure 3 shows the TEM bright field images and associated selected area electron diffraction (SAED) patterns including

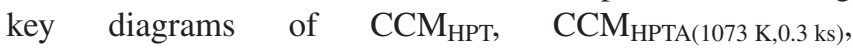

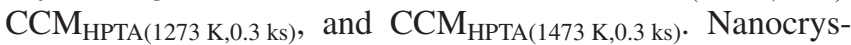
talline microstructures at the nanometer scale can be identified in $\mathrm{CCM}_{\mathrm{HPT}}$, and their existence is confirmed by the SAED pattern ${ }^{19,20)}$ in Fig. 3 (a). However, CCM ${ }_{\text {HPTA(1473 K,0.3 ks) }}$ exhibits a coarse-grained microstructure, and there is no existence of nanometer-scale grains. Two variants of $\varepsilon$ plates can be observed in $\mathrm{CCM}_{\mathrm{HPTA}(1073 \mathrm{~K}, 0.3 \mathrm{ks})}$. It is shown that the microstructure of $\mathrm{CCM}_{\mathrm{HPTA}(1273 \mathrm{~K}, 0.3 \mathrm{ks})}$ contains ultrafine grains at the micrometer level and hcp fringes according to Fig. 3 (a)

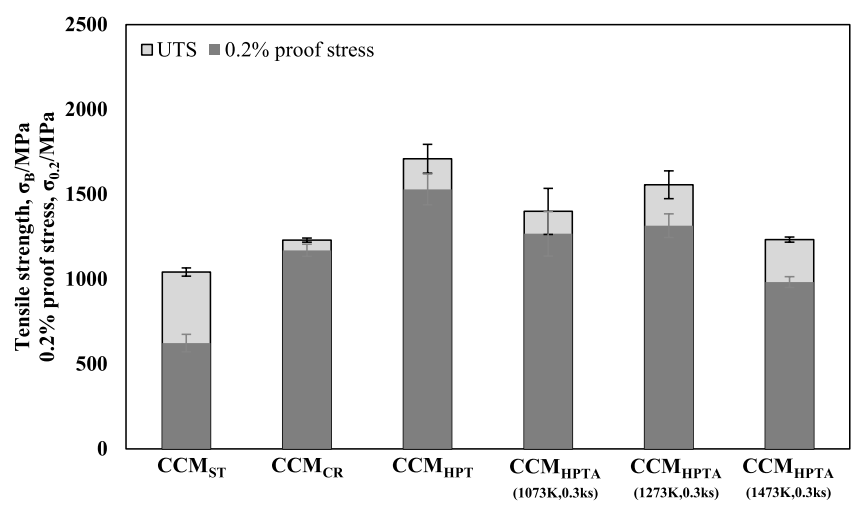

(b)

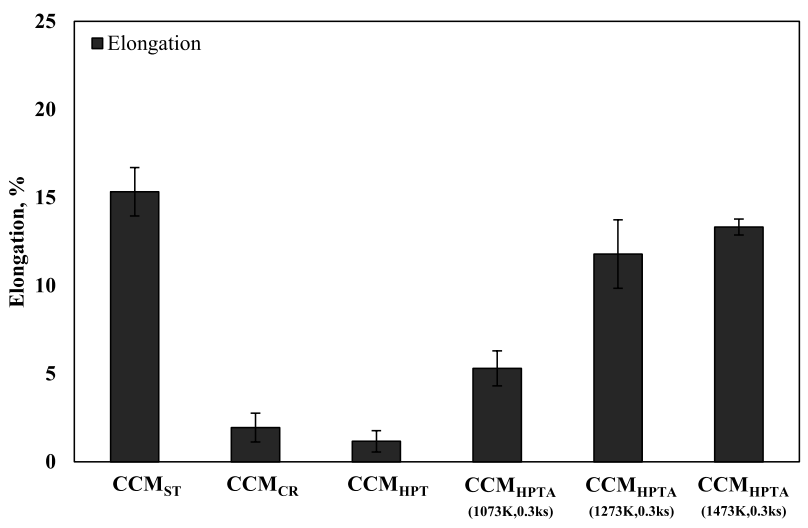

Fig. 4 (a) Tensile strength, $0.2 \%$ proof stress and (b) elongation of $\mathrm{CCM}_{\mathrm{ST}}$, $\mathrm{CCM}_{\mathrm{CR}}, \mathrm{CCM}_{\mathrm{HPT}}, \quad \mathrm{CCM}_{\mathrm{HPTA}(1073 \mathrm{~K}, 0.3 \mathrm{ks})}, \mathrm{CCM}_{\mathrm{HPTA}(1273 \mathrm{~K}, 0.3 \mathrm{ks})}$ and $\mathrm{CCM}_{\mathrm{HPTA}(1473 \mathrm{~K}, 0.3 \mathrm{ks})}$.

(c).

Tensile properties of $\mathrm{CCM}_{\mathrm{ST}}, \mathrm{CCM}_{\mathrm{CR}}, \mathrm{CCM}_{\mathrm{HPT}}$ and

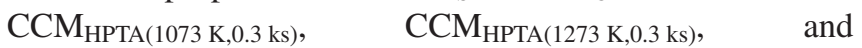
$\mathrm{CCM}_{\mathrm{HPTA}(1473 \mathrm{~K}, 0.3 \mathrm{ks})}$ are shown in Fig 4. The ultimate tensile strength (UTS) and $0.2 \%$ proof stress increase through HPT processing at $\mathrm{CCM}_{\mathrm{HPT}}$ compared to those in the ST condition. However, $\mathrm{CCM}_{\mathrm{HPT}}$ exhibits poor elongation. Subjecting 

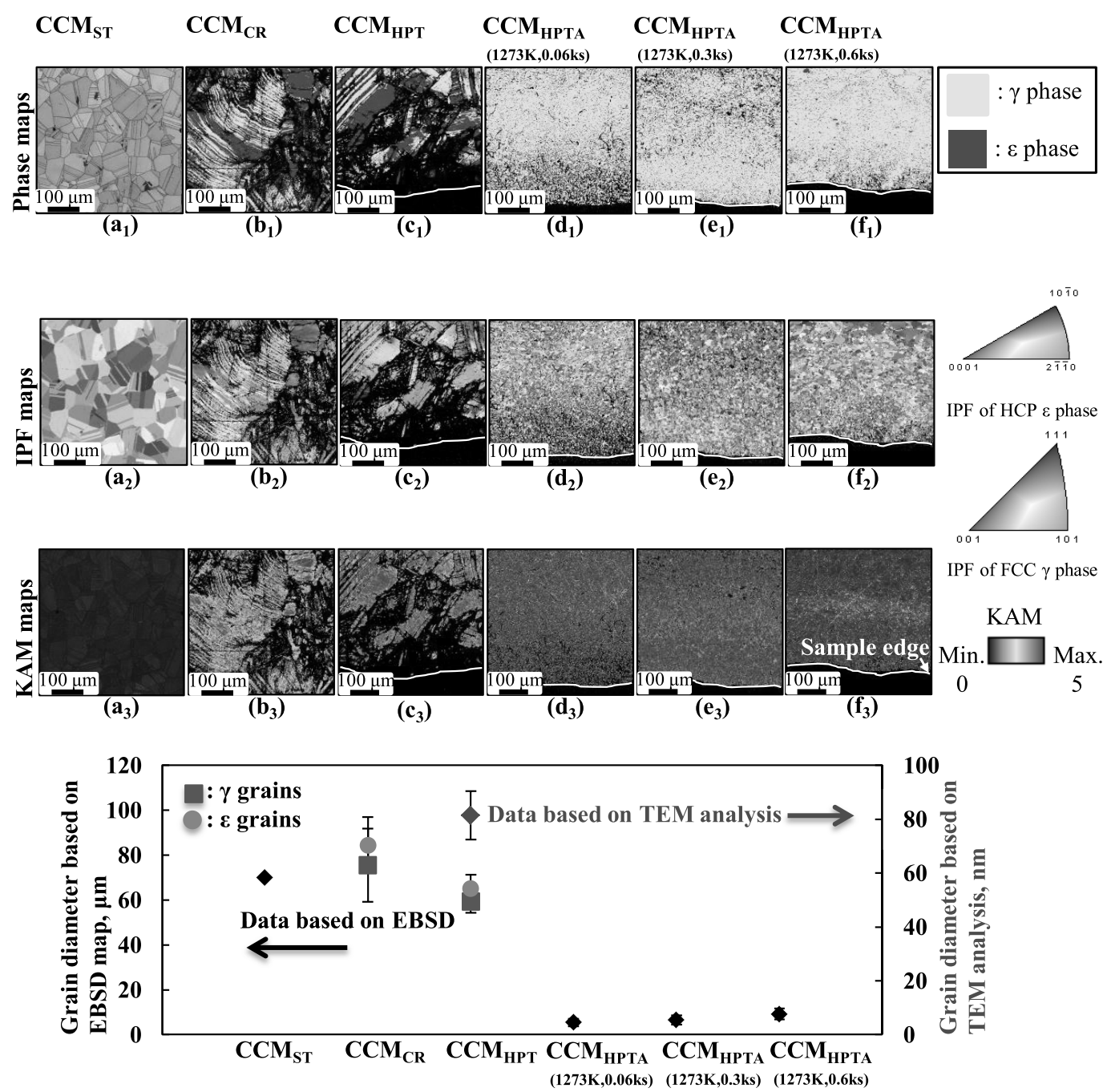

(g)

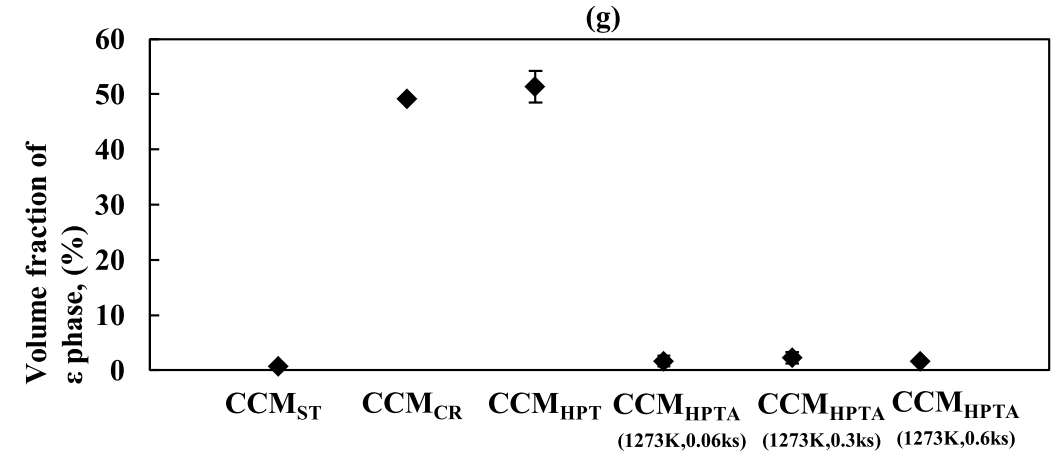

(h)

Fig. 5 EBSD $\left(\left(\mathrm{a}_{1}\right)-\left(\mathrm{f}_{1}\right)\right)$ phase, $\left(\left(\mathrm{a}_{2}\right)-\left(\mathrm{f}_{2}\right)\right)$ IPF and $\left(\left(\mathrm{a}_{3}\right)-\left(\mathrm{f}_{3}\right)\right)$ KAM maps and $(\mathrm{g})$ average grain diameter, and $(\mathrm{h})$ volume fraction of $\varepsilon$ phases of CCM

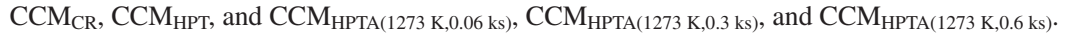

$\mathrm{CCM}_{\mathrm{HPT}}$ to a short annealing causes a decrease in the UTS and $0.2 \%$ proof stress. The elongation of $\mathrm{CCM}_{\mathrm{HPT}}$ is significantly improved with subsequent short annealing of $\mathrm{CCM}_{\mathrm{HPTA}(1073 \mathrm{~K}, 0.3 \mathrm{ks})}, \quad \mathrm{CCM}_{\mathrm{HPTA}(1273 \mathrm{~K}, 0.3 \mathrm{ks})}$ and

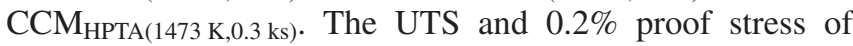
$\mathrm{CCM}_{\mathrm{HPTA}(1273 \mathrm{~K}, 0.3 \mathrm{ks})}$ are comparable with those of $\mathrm{CCM}_{\mathrm{HPT}}$, and higher than those of $\mathrm{CCM}_{\mathrm{HPTA}(1073 \mathrm{~K}, 0.3 \mathrm{ks})}$ and $\mathrm{CCM}_{\mathrm{HPTA}(1473 \mathrm{~K}, 0.3 \mathrm{ks})}$. Therefore, it is realized that the optimum temperature for a short annealing is $1273 \mathrm{~K}$ because $\mathrm{CCM}_{\mathrm{HPTA}(1273 \mathrm{~K}, 0.3 \mathrm{ks})}$ exhibits higher tensile strength and larger elongation compared to those of $\mathrm{CCM}_{\mathrm{HPTA}(1073 \mathrm{~K}, 0.3 \mathrm{ks})}$ and $\mathrm{CCM}_{\mathrm{HPTA}(1473 \mathrm{~K}, 0.3 \mathrm{ks}) \text {. }}$

\subsection{Effects of short annealing duration}

Figure 5 shows EBSD phase, IPF and KAM maps. Average grain diameter and volume fractions of $\varepsilon$ phases of $\mathrm{CCM}_{\mathrm{ST}}$, $\mathrm{CCM}_{\mathrm{CR}}, \quad \mathrm{CCM}_{\mathrm{HPT}}, \quad$ and $\mathrm{CCM}_{\mathrm{HPTA}(1273 \mathrm{~K}, 0.06 \mathrm{ks})}$,

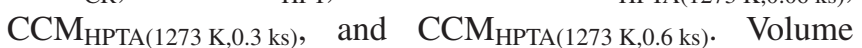
fraction of $\varepsilon$ phase is almost constant in $\mathrm{CCM}_{\mathrm{HPTA}}$ with different annealing duration. Recrystallized grains can be ob- 


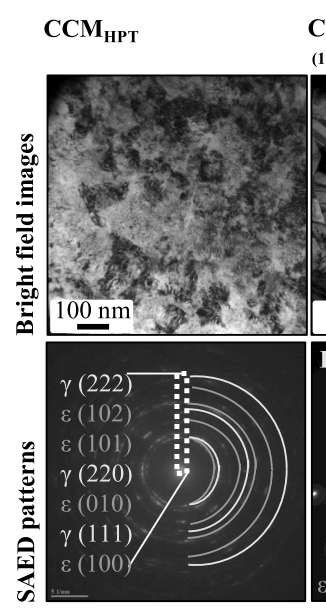

(a)

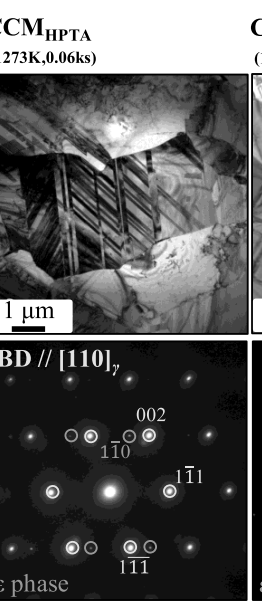

(b)

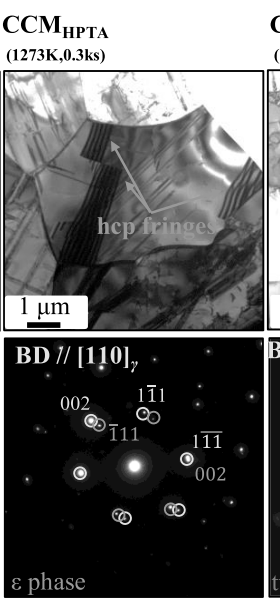

(c)

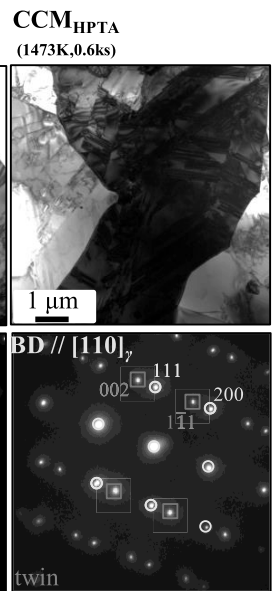

(d)

Fig. 6 TEM bright field images and SAED patterns of (a) $\mathrm{CCM}_{\mathrm{HPT}}$ and (b) $\mathrm{CMM}_{\mathrm{HPTA}(1273 \mathrm{~K}, 0.06 \mathrm{ks})}$, (c) $\mathrm{CCM}_{\mathrm{HPTA}(1273 \mathrm{~K}, 0.3 \mathrm{ks})}$ and (d) $\mathrm{CCM}$ HPTA(1273 K,0.6 ks). $\gamma$ phase, $\gamma$ twin and $\varepsilon$ phases are indicated in white, grey (square), and grey (circle), respectively, in the corresponding key diagrams of SAED patterns. Beam direction is parallel to $[110]_{\gamma}$ direction.

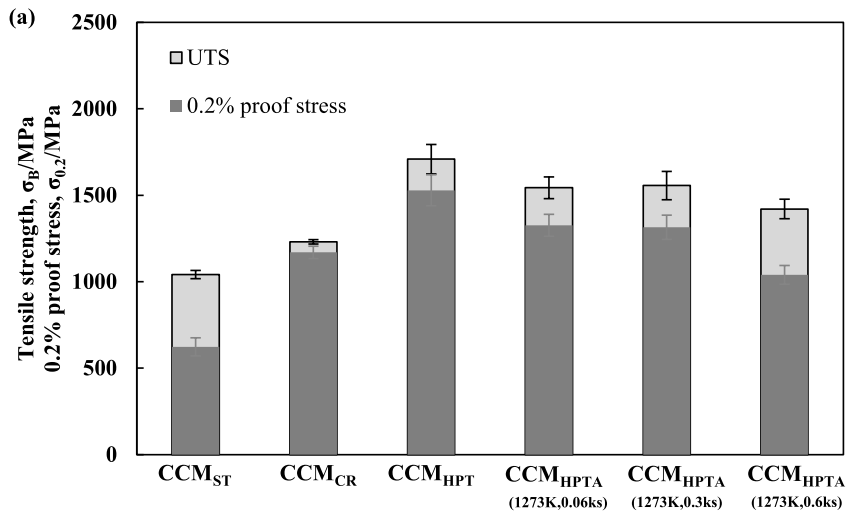

(b)

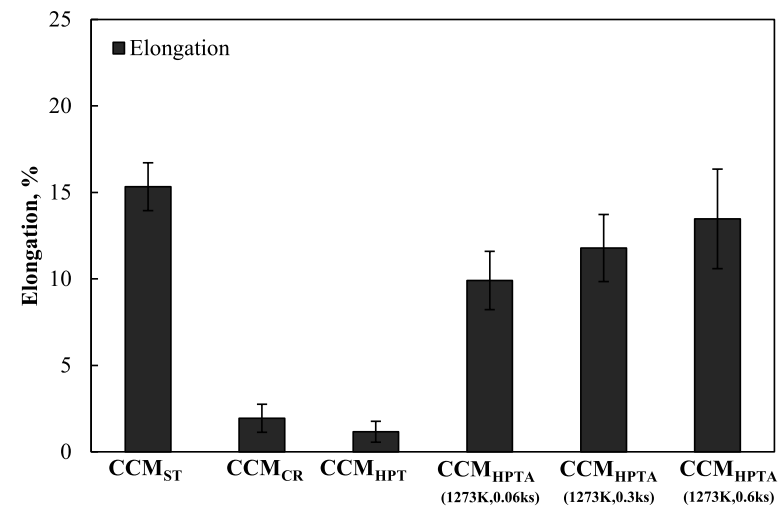

Fig. 7 (a) Tensile strength, $0.2 \%$ proof stress and (b) elongation of $\mathrm{CCM}_{\mathrm{ST}}$, $\mathrm{CCM}_{\mathrm{CR}}, \mathrm{CCM}_{\mathrm{HPT}}$ and $\mathrm{CCM}_{\mathrm{HPTA}(1273 \mathrm{~K}, 0.06 \mathrm{ks})}, \mathrm{CCM}_{\mathrm{HPTA}(1273 \mathrm{~K}, 0.3 \mathrm{ks}) \text {, and }}$ $\mathrm{CCM}_{\mathrm{HPTA}(1273 \mathrm{~K}, 0.6 \mathrm{ks})}$.

served in all of the $\mathrm{CCM}_{\mathrm{HPTA}}$ alloys. Average grain diameter of $\mathrm{CCM}_{\mathrm{HPTA}}$ increases with increasing short annealing time from $0.06 \mathrm{ks}$ to $0.6 \mathrm{ks}$. Average grain diameter of

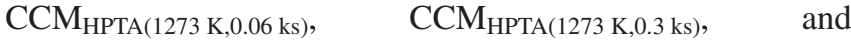
$\mathrm{CCM}_{\mathrm{HPTA}(1273 \mathrm{~K}, 0.6 \mathrm{ks})}$ are $5.4 \mu \mathrm{m}, 6.5 \mu \mathrm{m}$ and $9.2 \mu \mathrm{m}$, respectively. Further, the strain in $\mathrm{CCM}_{\mathrm{HPTA}}$ estimated from KAM value decreases with increasing the short annealing time from $0.3 \mathrm{ks}$ to $0.6 \mathrm{ks}$ based on EBSD KAM maps. Figure 6 shows

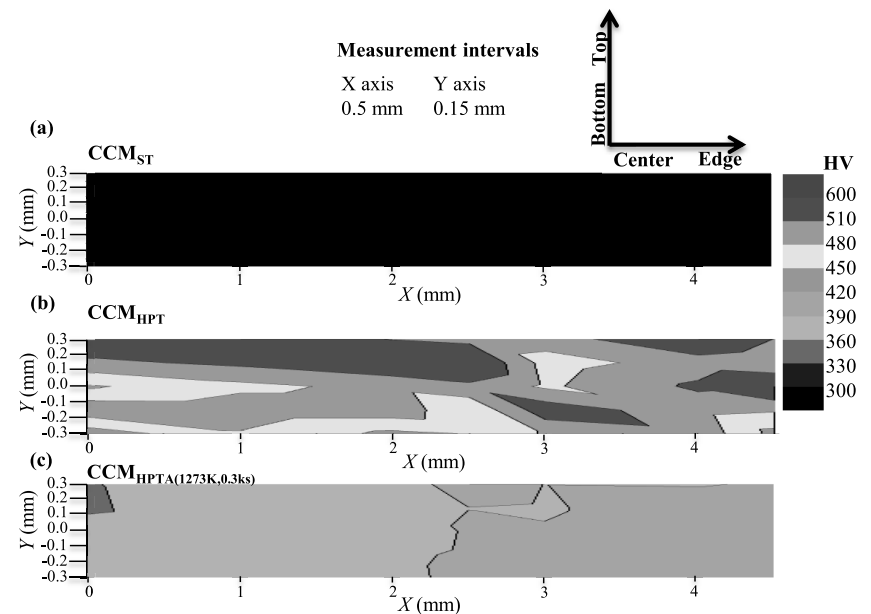

Fig. 8 Hardness distributions in cross sections of (a) $\mathrm{CCM}_{\mathrm{ST}}$, (b) $\mathrm{CCM}_{\mathrm{HPT}}$, and (c) $\mathrm{CCM}_{\mathrm{HPTA}(1273 \mathrm{~K}, 0.3 \mathrm{ks})}$.

the TEM bright field images and SAED patterns including

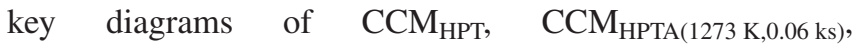

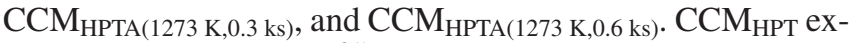
hibits a nanocrystalline ${ }^{21)}$ microstructure at the nanometer scale while $\mathrm{CCM}_{\mathrm{HPTA}}$ exhibits a fine-grained microstructure at the micrometer scale. Two variants of $\varepsilon$ plates can be observed in $\mathrm{CCM}_{\mathrm{HPT}}, \quad \mathrm{CCM}_{\mathrm{HPTA}(1273 \mathrm{~K}, 0.06 \mathrm{ks})}$ and $\mathrm{CCM}_{\mathrm{HPTA}(1273 \mathrm{~K}, 0.3 \mathrm{ks})}$. $\quad \varepsilon \quad$ martensite plates in $\mathrm{CCM}_{\mathrm{HPTA}(1273 \mathrm{~K}, 0.06 \mathrm{ks})}$ and hcp fringes in $\mathrm{CCM}_{\mathrm{HPTA}(1273 \mathrm{~K}, 0.3 \mathrm{ks})}$ can be observed. $\mathrm{CCM}_{\mathrm{HPTA}(1273 \mathrm{~K}, 0.6 \mathrm{ks})}$ shows a twin microstructure which is confirmed with SAED pattern according to Fig. 6 (d).

Figure 7 shows the tensile properties of $\mathrm{CCM}_{\mathrm{ST}}, \mathrm{CCM}_{\mathrm{CR}}$, $\mathrm{CCM}_{\mathrm{HPT}}, \mathrm{CCM}_{\mathrm{HPTA}(1273 \mathrm{~K}, 0.06 \mathrm{ks})}, \mathrm{CCM}_{\mathrm{HPTA}(1273 \mathrm{~K}, 0.3 \mathrm{ks}) \text {, and }}$ $\mathrm{CCM}_{\mathrm{HPTA}(1273 \mathrm{~K}, 0.6 \mathrm{ks})}$. The UTS and $0.2 \%$ proof stress of $\mathrm{CCM}_{\mathrm{HPTA}}$ do not significantly change with short annealing duration increasing from $0.06 \mathrm{ks}$ to $0.3 \mathrm{ks}$, and then they show a slight decrease with further increase of time to $0.6 \mathrm{ks}$. The elongation of $\mathrm{CCM}_{\mathrm{HPTA}}$ increases gradually with increasing short annealing time. Therefore, it is realized that subject- 


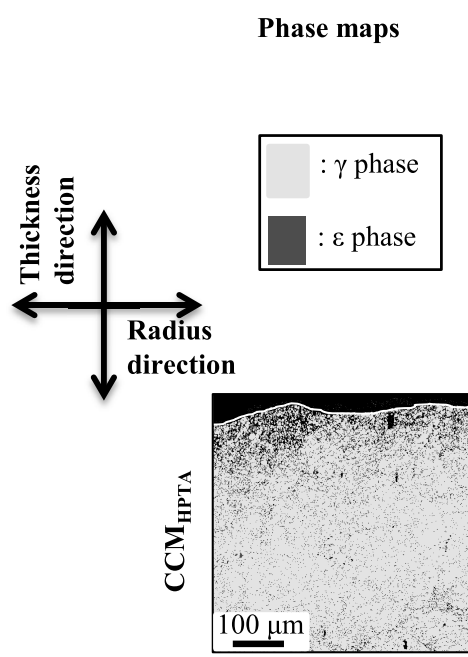

$\left(a_{1}\right)$

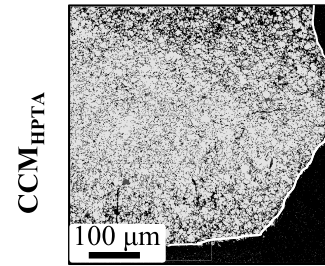

$\left(\mathbf{b}_{1}\right)$

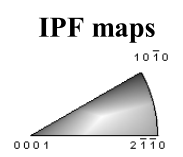
IPF of $\mathrm{HCP}_{111} \varepsilon$ phase

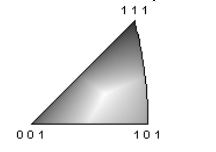

IPF of FCC $\gamma$ phase

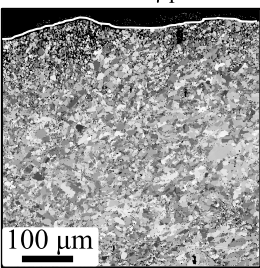

$\left(a_{2}\right)$

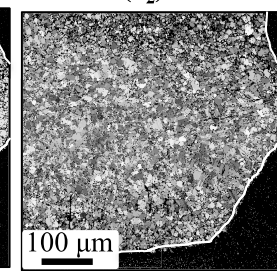

$\left(\mathbf{b}_{2}\right)$

KAM maps

KAM
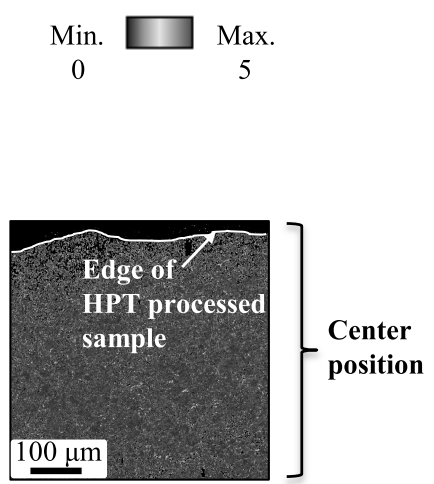

$\left(\mathbf{a}_{3}\right)$

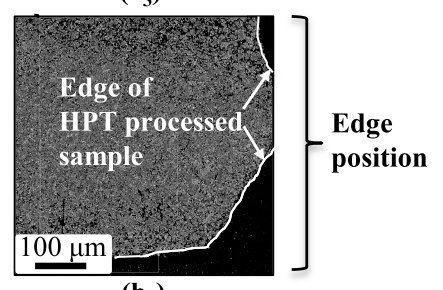

$\left(\mathbf{b}_{3}\right)$

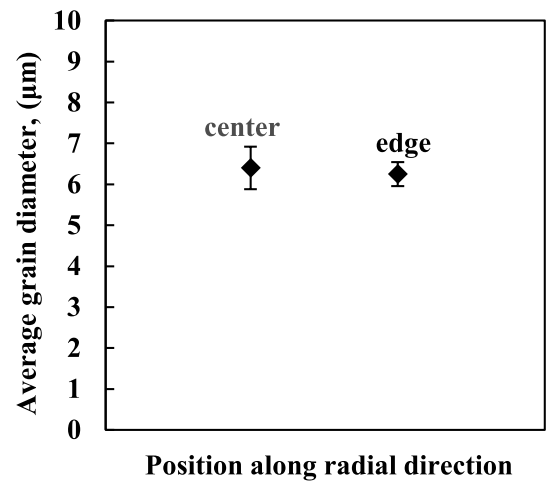

(c)

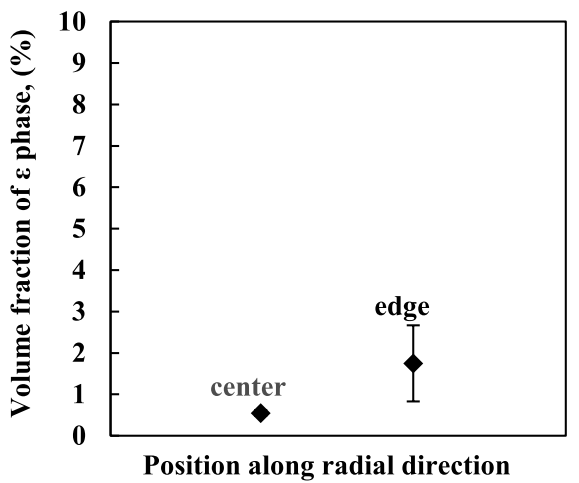

(d)

Fig. 9 EBSD $\left(\left(a_{1}\right)\right.$ and $\left.\left(b_{1}\right)\right)$ phase, $\left(\left(a_{2}\right)\right.$ and $\left.\left(b_{2}\right)\right)$ IPF, and $\left(\left(a_{3}\right)\right.$ and $\left.\left(b_{3}\right)\right)$ KAM maps of CCM $\mathrm{HPTA}_{(1273 \mathrm{~K}, 0.3 \mathrm{ks})}$ at center and edge positions of cross section along radial direction, (c) the evolution of average grain diameter, and (d) volume fraction of $\varepsilon$ phase in the cross section as a function of position through radial direction based on EBSD maps in $\left(\left(a_{1}\right)\right.$ and $\left.\left(b_{1}\right)\right)$.

ing $\mathrm{CCM}_{\mathrm{HPT}}$ to a short annealing at $1273 \mathrm{~K}$ for $0.3 \mathrm{ks}$ results in high tensile strength and larger elongation compared to

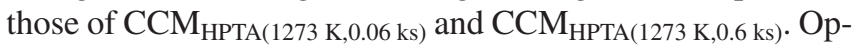
timized properties such as high strength and large elongation are obtained in $\mathrm{CCM}_{\mathrm{HPTA}(1273 \mathrm{~K}, 0.3 \mathrm{ks}) \text {, which is the best among }}$ the short annealing conditions examined. The hardness distribution of $\mathrm{CCM}_{\mathrm{HPTA}(1273 \mathrm{~K}, 0.3 \mathrm{ks})} \mathrm{ks}$ is investigated.

\subsection{Hardness distribution}

Figure 8 shows the hardness distribution for the cross sec-

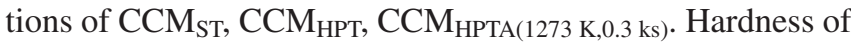
$\mathrm{CCM}_{\mathrm{ST}}$ is almost identical and around $300 \mathrm{HV}$ throughout the area of the cross section. Hardness value significantly increases through HPT processing for $\mathrm{CCM}_{\mathrm{HPT}}$ compared to that of the ST condition. Hardness of $\mathrm{CCM}_{\mathrm{HPTA}}$ is lower than that of the HPT condition, and it reaches around 360-420 HV. The hardness distribution of $\mathrm{CCM}_{\mathrm{HPTA}}$ suggests that the hardness is homogenous in the left-half region and right-half regions. In addition, the hardness is slightly higher in the righthalf region compared to that of left-half region in $\mathrm{CCM}_{\mathrm{HPTA}}$. Therefore, a detailed microstructure analysis was conducted to illuminate the abovementioned phenomenon (EBSD analyses in Fig. 9).

$\mathrm{CCM}_{\mathrm{HPTA}}$ exhibits a homogeneous hardness distribution on the cross section unlike the $\mathrm{CCM}_{\mathrm{HPT}}$ as evidenced in EBSD analyses in Fig. 9. The strain and volume fraction of $\varepsilon$ phase are slightly larger at the edge of cross section compared to that at the center of cross section of $\mathrm{CCM}_{\mathrm{HPTA}}$. Average grain diameters of $\mathrm{CCM}_{\mathrm{HPTA}}$ at different positions of cross section are almost same. 


\section{Discussion}

\subsection{Optimization of short annealing temperature}

It is well known that metallic materials are subjected to large strain during HPT processing and this large strain causes the formation of the $\varepsilon$ phase in the CCM alloy. ${ }^{2,13)}$ In $\gamma$ fcc phase of CCM alloy, with negative stacking fault energy, the glide of Shockley partial dislocations is an elementary deformation step which causes $\varepsilon \rightarrow \gamma$ martensitic transformation. $\varepsilon$-hcp martensitic phase is developed by regular overlapping of the stacking faults on every second $\left\{\begin{array}{lll}1 & 1 & 1\end{array}\right\}_{\gamma}$ plane. $\left.{ }^{2,13}\right)$ The volume fraction of the $\varepsilon$ phase in the CCM alloy severely increases through HPT processing compared to that of the ST condition (Fig. 2).

Figure 2 shows that the volume fraction of the $\varepsilon$ phase in $\mathrm{CCM}_{\mathrm{HPT}}$ is around $51 \%$ according to EBSD analyses. The volume fraction of the $\varepsilon$ phase slightly decreases for $\mathrm{CCM}_{\mathrm{HPTA}(1073 \mathrm{~K}, 0.3 \mathrm{ks})}$ compared to that of $\mathrm{CCM}_{\mathrm{HPT}}$, and it is around $31 \%$ according to Fig. 2. This decrease in volume fraction of $\varepsilon$ phase in $\mathrm{CCM}_{\mathrm{HPTA}(1073 \mathrm{~K}, 0.3 \mathrm{ks})}$ compared to $\mathrm{CCM}_{\mathrm{HPT}}$ is attributed to inhomogeneity of microstructure in specimens caused by HPT processing. Even the microstructure of $\mathrm{CCM}_{\mathrm{HPTA}(1073 \mathrm{~K}, 0.3 \mathrm{ks})}$ is inhomogeneous, excessive amount of $\varepsilon$ phase still exists in $\operatorname{CCM}_{\mathrm{HPTA}(1073 \mathrm{~K}, 0.3 \mathrm{ks})}$ and minimization of $\varepsilon$ phase could not be achieved in this condition. However, after subjecting $\mathrm{CCM}_{\mathrm{HPT}}$ to a short annealing at $1273 \mathrm{~K}$ and $1473 \mathrm{~K}$, the excessive $\varepsilon$ phase can be removed according to Fig. 2.

Figure 2 shows that $\mathrm{CCM}_{\mathrm{ST}}$ has a coarse-grained microstructure, whereas $\mathrm{CCM}_{\mathrm{HPT}}$ has visible grains and black areas which may be caused by high strain or grain refinement according to the EBSD maps. A previous study on CCM alloys ${ }^{14)}$ processed by HPT has reported that grain refinement occurs at CCM alloys processed by HPT to $\varepsilon_{\mathrm{eq}}=4.5,9$ and 45. Based on the TEM images in Fig. 3 and previous results, it is known that grain refinement also occurred at $\mathrm{CCM}_{\mathrm{HPT}}$, which was HPT processed to $\varepsilon_{\mathrm{eq}}=2.25$.

It is shown that $\mathrm{CCM}_{\mathrm{HPTA}(1073 \mathrm{~K}, 0.3 \mathrm{ks})}$ consists of visible grains and black areas similar to those in $\mathrm{CCM}_{\mathrm{HPT}}$ condition according to Fig. 2. In contrast to the case of $\mathrm{CCM}_{\mathrm{HPT}}$ (Fig. 3), no ultrafine-grained microstructure was found in TEM images of $\mathrm{CCM}_{\mathrm{HPTA}(1073 \mathrm{~K}, 0.3 \mathrm{ks})}$ although many areas were observed. Therefore, the black areas in the EBSD maps of $\mathrm{CCM}_{\mathrm{HPTA}(1073 \mathrm{~K}, 0.3 \mathrm{ks})}$ are considered to be areas where lattice distortion is too large for EBSD analysis rather than areas where grain size was too small for the EBSD analysis.

In the case of $\mathrm{CCM}_{\mathrm{HPTA}(1273 \mathrm{~K}, 0.3 \mathrm{ks})}$, the occurrence of recrystallization can be identified based on EBSD results in Fig. 2. A new microstructure develops homogeneously throughout the entire specimen. When severely deformed materials with high dislocation density are heated above approximately half of the melting point $\left(0.5 T_{\mathrm{m}}\right)$, recrystallization takes place. Static recovery takes place during the early stage of annealing for the severely deformed materials, which is responsible for the development of recrystallization nuclei as fine dislocation-free crystallites. Grain growth caused by the migration of the boundaries results in consumption of the highly strained microstructure. ${ }^{22-26)}$ Recrystalization process causes a homogeneous microstructure ${ }^{27,28)}$ which is consistent with abovementioned corresponding results.
In addition, the refinement of coarse-grains in $\mathrm{CCM}_{\mathrm{HPTA}(1273 \mathrm{~K}, 0.3 \mathrm{ks})}$ is also possible to be occured by short annealing. Previously, it was reported that grain refinement might occur via $\varepsilon \rightarrow \gamma$ reverse transformation via solution treatment. The effect of refinement caused by short annealing exists by some extent ${ }^{29}$ ).

Recrystallization did not occur for $\mathrm{CCM}_{\mathrm{HPTA}(1073 \mathrm{~K}, 0.3 \mathrm{ks}) \text {. }}$ This indicates that the annealing temperature is not enough to achieve recrystallization, even though it was above $0.5 T_{\mathrm{m}}=$ $\sim 973 \mathrm{~K}$ for the CCM alloy. This is because recrystallization is not only determined by the temperature, but also depends on material factors such as the type of lattice, concentration of alloying elements, and size distributions of second phases. ${ }^{30)}$

Corresponding results in Fig. 2 also suggest that increasing the temperature for short annealing causes progressive coarsening of the grains for $\mathrm{CCM}_{\mathrm{HPTA}(1473 \mathrm{~K}, 0.3 \mathrm{ks}) \text {, and the grains }}$ become excessively larger compared to those of $\mathrm{CCM}_{\mathrm{HPTA}(1273 \mathrm{~K}, 0.3 \mathrm{ks})}$.

Figure 4 suggests that the UTS and $0.2 \%$ proof stress of the CCM alloy increase while the elongation decreases through HPT processing compared to those of $\mathrm{CCM}_{\mathrm{ST}}$. Based on previous studies, it can be inferred that HPT processing causes an increase in the tensile strength owing to grain refinement, and an increase in volume fraction of the $\varepsilon$ phase and in dislocation density. ${ }^{14,31-35)}$

The UTS and $0.2 \%$ proof stress of $\mathrm{CCM}_{\mathrm{HPTA}(1073 \mathrm{~K}, 0.3 \mathrm{ks})}$ are lower than to those of the $\mathrm{CCM}_{\mathrm{HPT}}$. $\mathrm{CCM}_{\mathrm{HPTA}(1073 \mathrm{~K}, 0.3 \mathrm{ks})}$ exhibits an excessive volume fraction of the $\varepsilon$ phase and does not show an ultrafine-grained microstructure, which causes a lower elongation compared to $\operatorname{CCM}_{\mathrm{HPTA}(1273 \mathrm{~K}, 0.3 \mathrm{ks})}$ and $\mathrm{CCM}_{\mathrm{HPTA}(1473 \mathrm{~K}, 0.3 \mathrm{ks})} .{ }^{35,36)}$

The UTS and $0.2 \%$ proof stress of $\mathrm{CCM}_{\mathrm{HPTA}(1273 \mathrm{~K}, 0.3 \mathrm{ks})}$ are higher than those of $\mathrm{CCM}_{\mathrm{ST}}, \mathrm{CCM}_{\mathrm{CR}}$, and $\mathrm{CCM}_{\mathrm{HPTA}(1473 \mathrm{~K}, 0.3 \mathrm{ks}) \text {, and comparable with those of } \mathrm{CCM}_{\mathrm{HPT}}}$

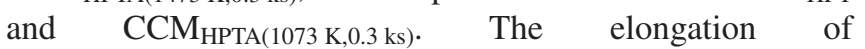
$\mathrm{CCM}_{\mathrm{HPTA}(1273 \mathrm{~K}, 0.3 \mathrm{ks})}$ and $\mathrm{CCM}_{\mathrm{HPTA}(1473 \mathrm{~K}, 0.3 \mathrm{ks})}$ is larger than that of other samples except for that of the $\mathrm{CCM}_{\mathrm{ST}}$. Therefore, it is concluded that $1273 \mathrm{~K}$ is the optimum temperature for a short annealing with the fixed duration of $0.3 \mathrm{ks}$ because of the high strength and large elongation obtained for

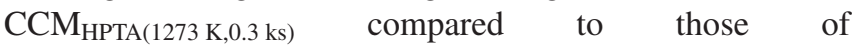
$\mathrm{CCM}_{\mathrm{HPTA}(1073 \mathrm{~K}, 0.3 \mathrm{ks})}$. In addition, the effect of HPT rotation number $(N=0.25,0.5,1,2$ and 5$)$ on the mechanical properties of CCM alloy is able to be discussed in this section. It has been reported that tensile strength of $\mathrm{CCM}_{\mathrm{HPT}}$ almost keeps constant from $N=0.25\left(\varepsilon_{\mathrm{eq}}=2.25\right)$ to $N=1\left(\varepsilon_{\mathrm{eq}}=9\right)$, then it decreases when $N$ exceeds 1 . The elongation of $\mathrm{CCM}_{\mathrm{HPT}}$ at each rotation number shows a similar value of $\sim 1-2 \%$. Therefore, even though the rotation of 90 degrees $(N=0.25)$ might seem to be rather small, the mechanical properties of $\mathrm{CCM}_{\mathrm{HPT}}$ at $N=0.25$ is optimized compared to those of $\mathrm{CCM}_{\mathrm{HPT}}$ with higher rotation number ${ }^{14,18}$. In this study, the mechanical properties of short annealed $\mathrm{CCM}_{\mathrm{CR}}$ were not evaluated. The microstructure of short annealed $\mathrm{CCM}_{\mathrm{CR}}$ was investigated. The average grain diameter was $\sim 41 \mu \mathrm{m}$ and $\varepsilon$ phase with a volume fraction of $\sim 37 \%$ could be detected. Therefore, short annealed $\mathrm{CCM}_{\mathrm{CR}}$ was expected not to exhibit greater mechanical properties due to coarse-grained microstructure and excessive volume fraction of $\varepsilon$ phase. Nanocrystalline microstructure cannot be obtained in CCM alloy using cold rolling 
process or conventional hot forging ${ }^{37)}$, while it can be obtained using $\mathrm{HPT}^{14)}$. Previously, $\mathrm{CCM}_{\mathrm{HPT}}\left(N=0.25\left(\varepsilon_{\mathrm{eq}}=\right.\right.$ 2.25)) was compared with hot forged $\mathrm{CCM}$ alloy $\left(\mathrm{CCM}_{\mathrm{HF}}\right)$ reported by Yamanaka et al., which has one of the smallest grain diameters among CCM alloys reported in literatures ${ }^{37)}$. UTS and $0.2 \%$ proof stress of $\mathrm{CCM}_{\mathrm{HPT}}(\sim 1709 \mathrm{MPa}$ and $\sim 1528 \mathrm{MPa})$ are greater than those of $\mathrm{CCM}_{\mathrm{HF}}$ $(\sim 1450 \mathrm{MPa}$ and $\sim 1330 \mathrm{MPa})$. In addition, Vickers hardness of $\mathrm{CCM}_{\mathrm{HPT}}$ at half radius $(\sim 503 \mathrm{HV})$ is greater than that of $\mathrm{CCM}_{\mathrm{HF}}(\sim 428 \mathrm{HV})$ reported for CCM alloy in practical use ${ }^{5)}$. Therefore, it can be concluded that HPT processing helps to achieve greater tensile strength and hardness in CCM alloys than cold rolling and hot forging. The main target of this study was to improve the elongation of $\mathrm{CCM}_{\mathrm{HPT}}$ and maintain a high strength using a subsequent short annealing, which was used to minimize the $\varepsilon$ phase while maintaining nanocrystalline microstructure. Although nanocrystalline microstructure was not able to be maintained with short annealing, the elongation of HPT processed CCM was significantly improved (from ( $\sim 1 \%$ to $\sim 12 \%$ ) while the UTS (from $\sim 1709 \mathrm{MPa}$ to $\sim 1556 \mathrm{MPa}$ ) and $0.2 \%$ proof stress (from $\sim 1528 \mathrm{MPa}$ to $\sim 1315 \mathrm{MPa}$ ) only relatively slightly decreased.

\subsection{Optimization of short annealing duration}

The volume fractions of the $\varepsilon$ phase are almost $0 \%$ in all the $\mathrm{CCM}_{\mathrm{HPTA}}$ with different annealing times. The average grain diameter of $\mathrm{CCM}_{\mathrm{HPTA}}$ slightly increases owing to grain growth caused by the migration of the boundaries, ${ }^{22-26)}$ while strain decreases with increasing short annealing time, which can be identified in Fig. 5.

The UTS and $0.2 \%$ proof stress of $\mathrm{CCM}_{\mathrm{HPTA}(1273 \mathrm{~K}, 0.06 \mathrm{ks})}$ and $\mathrm{CCM}_{\mathrm{HPTA}(1273 \mathrm{~K}, 0.3 \mathrm{ks})}$ are almost same according to Fig. 7. This is because the average grain diameter and volume fraction of the $\varepsilon$ phase are similar to those of $\mathrm{CCM}_{\mathrm{HPTA}(1273 \mathrm{~K}, 0.06 \mathrm{ks})}$

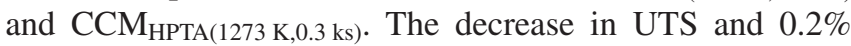
proof stress and increase in elongation of $\mathrm{CCM}_{\mathrm{HPTA}(1273 \mathrm{~K}, 0.6 \mathrm{ks})}$ are attributed to an increase in grain size.

\subsection{Effect of HPT and subsequent short annealing on hardness distribution}

Figure 8 shows that the hardness (HV) of a CCM alloy significantly increases through HPT processing compared to that of $\mathrm{CCM}_{\mathrm{ST}}$. This increase in the hardness is attributed to grain refinement, accumulation of dislocations and strain induced martensite. ${ }^{14,34)} \mathrm{CCM}_{\mathrm{HPT}}$ exhibits a heterogeneous hardness distribution on the cross section, which is shown in Fig. 8. This heterogeneity in hardness distribution is attributed to the heterogeneous microstructure caused by unusual plastic flow patterns during HPT. ${ }^{38-40)}$ Hardening occurs at the surface of the HPT processed specimen owing to martensitic transformations, accumulation of dislocation and grain refinement. This hardening may prevent strain from developing deeply below the specimen's surface, causing the heterogeneity in the microstructure. ${ }^{14)}$

In the case of $\mathrm{CCM}_{\mathrm{HPTA}}$, a homogeneous hardness distribution can be obtained in the left-half region (close to the center) and the right-half region (close to the edge) of the cross section. The hardness of the right-half region is slightly higher than that of the left-half region. The increase in the strain and the volume fraction of the $\varepsilon$ phase at the edge of the spec- imen compared to that in the center of the specimen can be identified in Fig. 9. This result can explain the increase in hardness at the edge of the $\mathrm{CCM}_{\mathrm{HPTA}}$ specimen.

\section{Conclusions}

In this study, a CCM alloy was subjected to HPT processing and a subsequent short annealing under various conditions in order to optimize its mechanical properties. The microstructure and mechanical properties were investigated. The obtained results are as follows:

(1) $\gamma \rightarrow \varepsilon$ martensitic transformation and grain refinement induced by HPT processing increase the tensile strength of the CCM alloy. However, HPT processing decreases the elongation.

(2) An optimized mechanical property, which is a combination of high strength and large elongation, is achieved for $\mathrm{CCM}_{\mathrm{HPTA}(1273 \mathrm{~K}, 0.3 \mathrm{ks})}$. This is attributed to the minimization of the volume fraction of the $\varepsilon$ phase and maintaining the fine-grained microstructure in $\mathrm{CCM}_{\mathrm{HPTA}(1273 \mathrm{~K}, 0.3 \mathrm{ks}) \text {. }}$

(3) Subjecting $\mathrm{CCM}_{\mathrm{HPT}}$ to a short annealing at $1273 \mathrm{~K}$ for 0.3 ks causes a decrease in hardness (HV) but a more homogeneous hardness distribution compared to those of $\mathrm{CCM}_{\mathrm{HPT}}$.

\section{Acknowledgements}

This study was supported in part by a Grant-in-Aid for Scientific Research (A) No. 24246111 from the Japan Society for the Promotion of Science (JSPS) and the Inter-University Cooperative Research Program "Innovation Research for Biosis-Abiosis Intelligent Interface” from the Ministry of Education, Culture, Sports, Science and Technology (MEXT), Japan. The HPT process was carried out in the International Research Center on Giant Straining for Advanced Materials (IRC-GSAM) at Kyushu University.

\section{REFERENCES}

1) S.H. Sun, Y. Koizumi, S. Kurosu, Y.P. Li, H. Matsumoto and A. Chiba: Acta Mater. 64 (2014) 154-68.

2) K. Yamanaka, M. Mori and A. Chiba: Acta Biomater. 9 (2013) 625967.

3) A. Chiba, K. Kumagai, N. Nomura and S. Miyakawa: Acta Mater. 55 (2007) 1309-18.

4) Y. Koizumi, S. Suzuki, K. Yamanaka, B.S. Lee, K. Sato, Y. Li, S. Kurosu, H. Matsumoto and A. Chiba: Acta Mater. 61 (2013) 1648-61.

5) Y. Koizumi, Y. Chen, Y. Li, K. Yamanaka, A. Chiba, S.I. Tanaka and Y. Hagiwara: Mater. Sci. Eng. C 62 (2016) 532-543.

6) K. Yamanaka, M. Mori, S. Kurosu, H. Matsumoto and A. Chiba: Metall. Mater. Trans., A 40 (2009) 1980-1994.

7) P.W. Bridgman: Phys. Rev. 48 (1935) 825-847.

8) P.H.R. Pereira, R.B. Figueiredo, P.R. Cetlin and T.G. Langdon: Mater. Sci. Eng. A 631 (2015) 201-8.

9) R.Z. Valiev and T.G. Langdon: Prog. Mater. Sci. 51 (2006) 881-981.

10) A.P. Zhilyaev and T.G. Langdon: Prog. Mater. Sci. 53 (2008) 893-979.

11) H. Yilmazer, M. Niinomi, K. Cho, M. Nakai, J. Hieda, S. Sato and Y. Todaka: Acta Mater. 80 (2014) 172-82.

12) R.B. Figueiredo and T.G. Langdon: Mater. Sci. Eng. A 528 (2011) 4500-4506.

13) K.Yamanaka, M. Mori, Y. Koizumi, and A. Chiba: J. Mech. Behav. Biomed. Mater., 2014, vol. 32, pp. 52-61.

14) M. Isik, M. Niinomi, K. Cho, H. Liu, M. Nakai, H. Yilmazer, Z. Horita and T. Narushima: J. Mech. Behav. Biomed. Mater. 59 (2016) 226-35.

15) H. Matsumoto, S. Kurosu, B.S. Lee, Y. Li and A. Chiba: Scr. Mater. 63 
(2010) 1092-1095.

16) H. Matsumoto, Y. Koizumi, T. Ohashi, B.S. Lee, Y. Li and A. Chiba: Acta Mater. 64 (2014) 1-11.

17) R. Ueji, N. Tsuji, T. Ohashi, Y. Minamino and Y. Koizumi: Sci. Technol. Adv. Mater. 5 (2004) 153-162.

18) M. Isik, M. Niinomi, H. Liu, K. Cho, M. Nakai, Z. Horita, T. Narushima, H. Yilmazer and M. Nagasako: Mater. Trans. 57 (2016) 1109-1118.

19) D.K. Yang, P. Cizek, P.D. Hodgson and C.E. Wen: Acta Mater. 58 (2010) 4536-48.

20) N. Hansen: Scr. Mater. 51 (2004) 751-53.

21) Q. Wei, S. Cheng, K.T. Ramesh and E. Ma: Mater. Sci. Eng. A 381 (2004) 71-79.

22) F. J. Humphreys and M. Hatherly: Recrystallization and related phenomena, Australia, 2004

23) R. D. Doherty, D. A. Hughes, F. J. Humphreys, J. J. Jonas, D. J. Jensen, M. E. Kassner, W. E. King, T. R. McNelley, H. J. McQueen, and A.D. Rollett: Mater. Today, 1998.

24) J.E. Burke and D. Turnbull: Prog. Met. Phys. 3 (1952) 220-92.

25) J.E. Bailey: Proc. Roy. Soc. (London), Ser. A 267 (1962) 11-30.

26) T. Sakai, A. Belyakov, R. Kaibyshev, H. Miura and J.J. Jonas: Prog. Mater. Sci. 60 (2014) 130-207.

27) E. Hornbogen and U. Koster: Dr. Riederer-Verlag, Gmbh (Stuttgart), 1978, pp. 159-94.
28) H. Ahlborn, E. Hornbogen and U. Köster: J. Mater. Sci. 4 (1969) 94450 .

29) S. Kurosu, H. Matsumoto and A. Chiba: Mater. Lett. 64 (2010) 49-52.

30) J. R. Davis and A.S.M.I.H. Committee: Nickel, Cobalt, and Their Alloys, ASM International, 2000.

31) P.H.R. Pereira, R.B. Figueiredo, P.R. Cetlin and T.G. Langdon: Mater. Sci. Eng. A 631 (2015) 201-8

32) S. Gourdet and F. Montheillet: Acta Mater. 51 (2003) 2685-99.

33) Y. Mine, S. Matsumoto and Z. Horita: Corros. Sci. 53 (2011) 2969-77.

34) R.Z. Valiev, E.V. Kozlov, Y.F. Ivanov, J. Lian, A.A. Nazarov and B. Baudelet: Acta Metall. Mater. 42 (1994) 2467-75.

35) T. Mitsunobu, Y. Koizumi, B.S. Lee, K. Yamanaka, H. Matsumoto, Y. Li and A. Chiba: Acta Mater. 81 (2014) 377-85.

36) K. Edalati, S. Toh, M. Arita, M. Watanabe and Z. Horita: Appl. Phys. Lett. 102 (2013) 181902-181906.

37) K. Yamanaka, M. Mori and A. Chiba: Mater. Sci. Eng. A 528 (2011) 5961-5966.

38) Y. Cao, Y.B. Wang, S.N. Alhajeri, X.Z. Liao, W.L. Zheng, S.P. Ringer, T.G. Langdon and Y.T. Zhu: J. Mater. Sci. 45 (2010) 765-70.

39) R.B. Figueiredo and T.G. Langdon: Mater. Sci. Eng. A 528 (2011) 4500-4506.

40) M. Kawasaki, R.B. Figueiredo and T.G. Langdon: Acta Mater. 59 (2011) 308-16. 